\title{
INSTRUMENTOS DEL MUSEO SARACÍBAR (I.O.B.A.). EL DISCO DE PLÁCIDO
}

\author{
ROJO A ${ }^{1}$, PARÍS E ${ }^{2}$
}

La imagen de este instrumento ha servido de reclamo en los carteles y folletos de mano de la exposición que el I.O.B.A. vallisoletano ha celebrado en 2007 en el Sala de Exposiciones de la Caja de España de Valladolid. Titulada Ciencia y Técnica. Instrumental Oftalmológico. Museo Saracíbar; mediante ella, entre los días 9 y 28 de octubre, se mostraron al gran público parte de los más de dos-

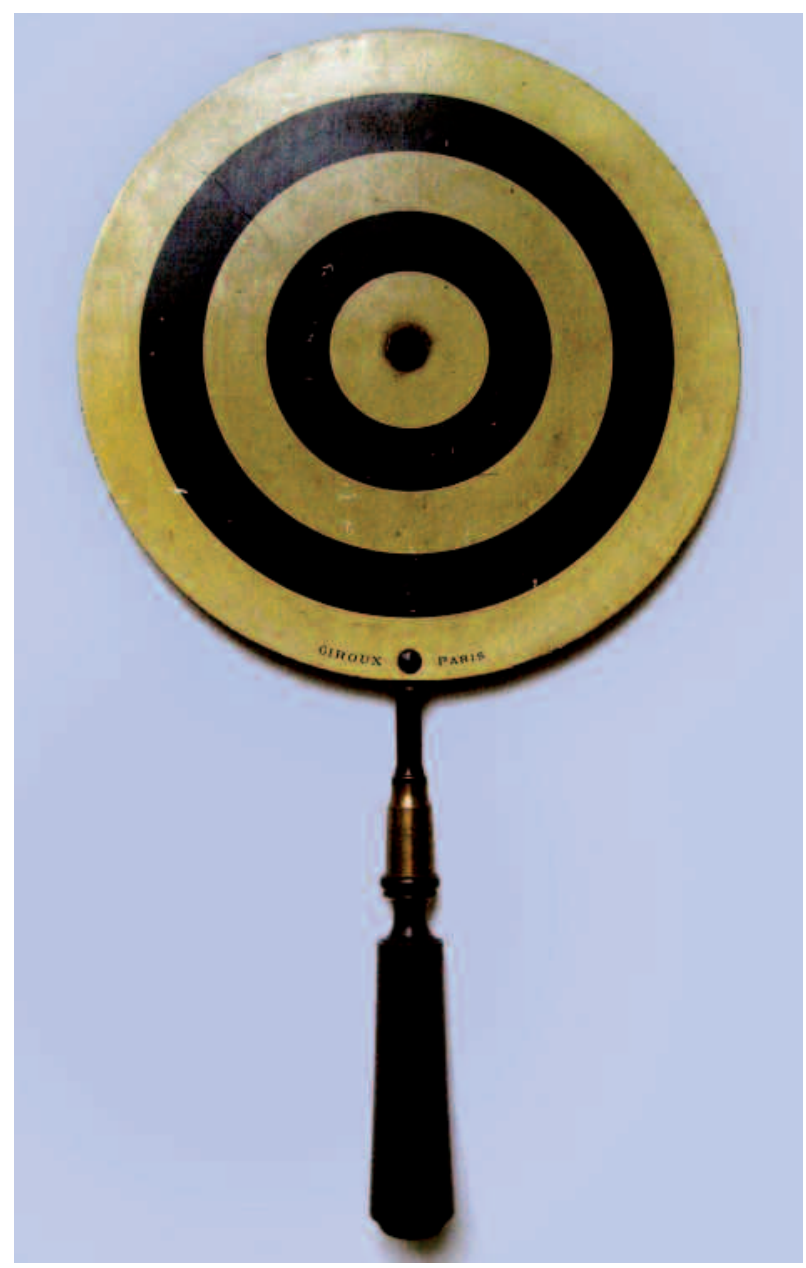

Disco de Plácido - Museo Sarasíbar IOBA. cientos instrumentos antiguos de oftalmología, libros y elementos diversos que conforman el Museo de oftalmología «Doctor Saracíbar» integrado desde 1995 en el Instituto Universitario de Oftalmobiología Aplicada.

La colección parte de una donación inicial efectuada por el doctor José María Saracíbar, miembro de una familia vallisoletana cuya tradición médica arranca del año 1871, a la que se han ido incorporando posteriormente otras, como la última y reciente por parte de la viuda del doctor Jaime Pérez-Llorca Rodrigo, de Cádiz.

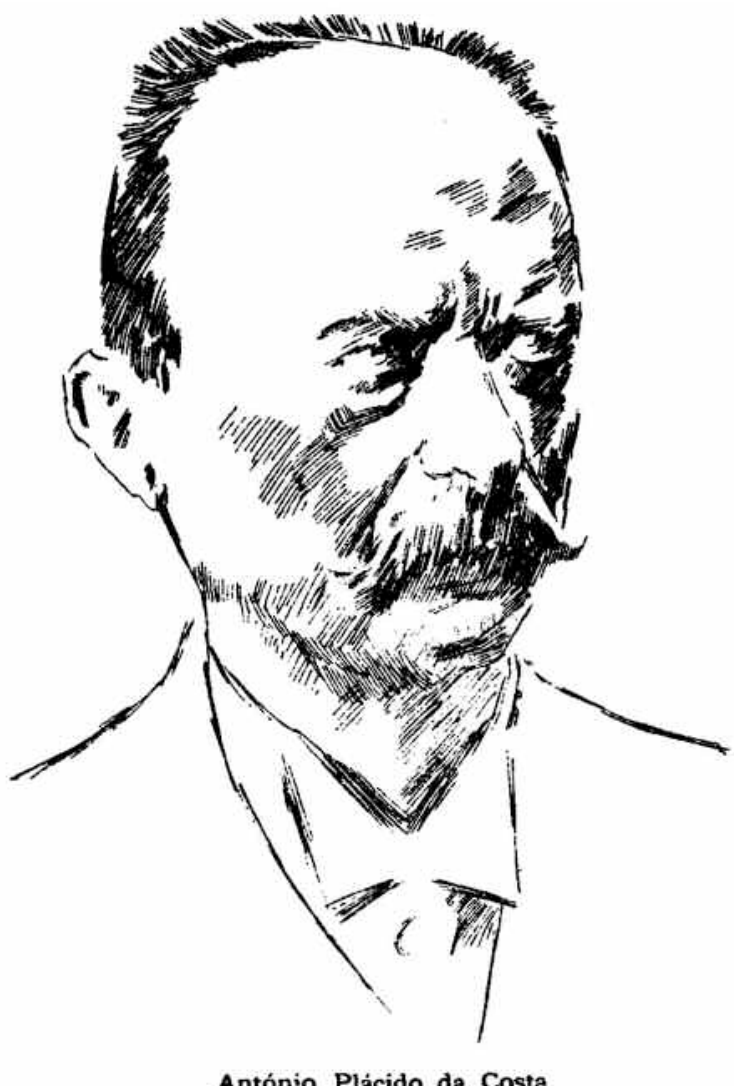

Plácido da Costa.

\footnotetext{
1 rojo@ioba.es

2 emparis@ioba.med.uva.es
} 

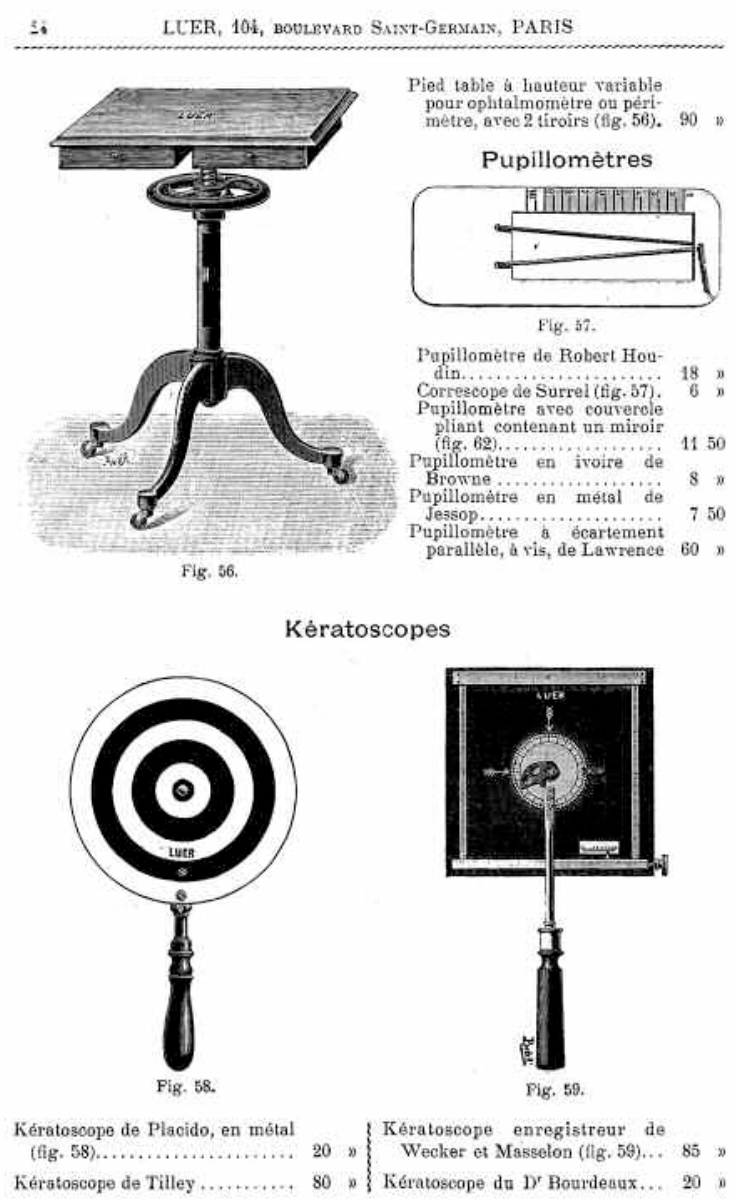

Disco de Plácido. Catálogo Luer, 1909.

El artefacto presentado en esta página iconográfica pertenece al conjunto inicial, siendo un instrumento datable hacia 1910 y fabricado en torno a 1910 por la casa Giroux de París. Es un Keratoscopio. Un conjunto de círculos alternativos blancos y negros montados sobre una plancha circular que permiten examinar la curvatura de la córnea.

Fue inventado por el médico portugués Antonio Plácido da Costa (1848-1915), de ahí que sea comúnmente conocido como Disco de Plácido. Todavía hoy sigue sirviendo de base a algunos aparatos de diagnóstico oftalmológico que, con la ayuda de programas informáticos, realizan estudios y análisis topográficos de la córnea; sea ejemplo el Orbscan II.

El inventor, como todo buen sabio y santo que se precie, nació en el seno de una familia humilde, en Covilha, y solamente pudo llegar a ser lo que fue gracias a su absorción por una campaña religiosa de captación de nuevas vocaciones que le llevó al semina-

\section{Tangent Scales, etc.}

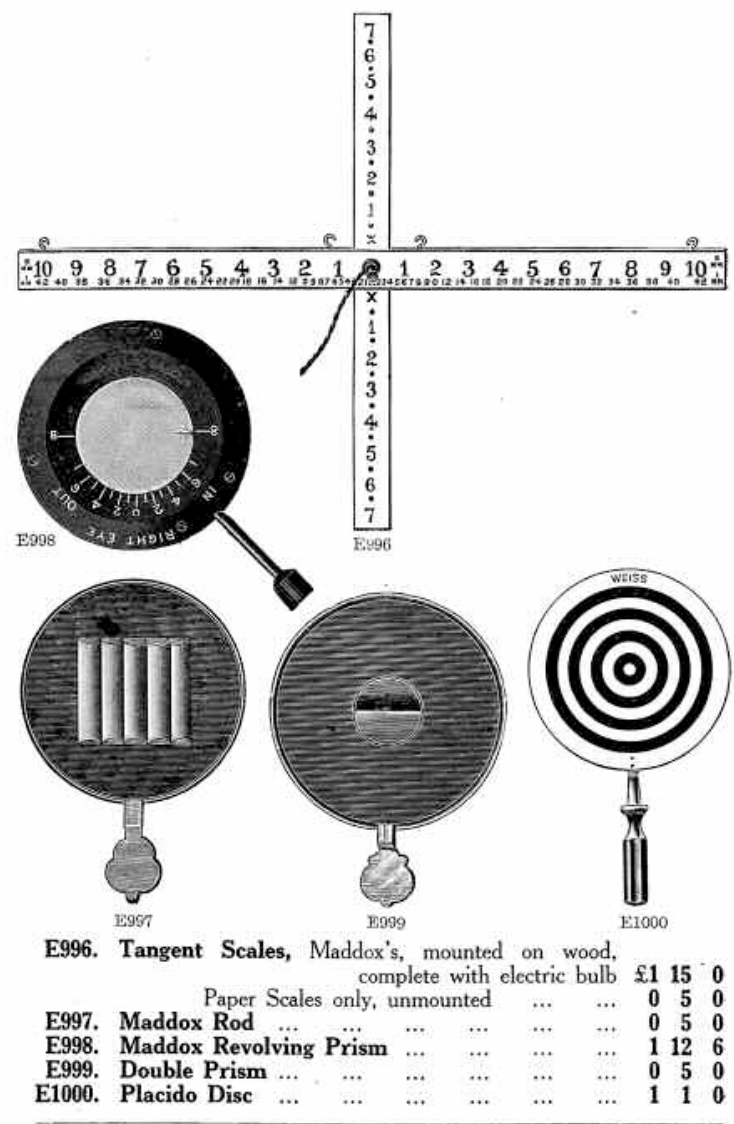

287, OXFORD STREET, LONDON, $W$.

\section{Disco de Plácido. Catálogo John Weiss, 1916.}

rio de Cambray en Francia. Estaba ya preparado para la definitiva vida de los claustros cuando la guerra franco-prusiana de 1870 le devolvió a Portugal.

Convencido de su falta de vocación, pasó entonces a estudiar medicina en la Escola Medico-Cirúrgica do Porto y en dicha ciudad se convirtió en el pionero de la microbiología médica portuguesa. Más tarde el oftalmólogo Pedro Adriano Van der Laan le introdujo en los caminos de la oftalmología y en el curso de su práctica desarrolló el disco, presentado a la sociedad científica internacional en el número de septiembre-noviembre de 1880 del Periódico de Oftalmología Prática.

Hubo polémica. Mientras Hirschberg le apoyaba en Alemania, Javal negaba su prioridad en Francia. Hoy se da por zanjada la polémica y se reconoce a Plácido como genuino inventor del disco de Plácido. 